\title{
A Study on the Culture and Tourism Spatial Production of Ethnic Villages in the Tourism for Poverty Alleviation
}

\author{
Ping Zhao ${ }^{1 *}$ \\ Yinxing Hospitality Management College of CUIT, Chengdu, Sichuan 611743, China \\ *zhaoping@yxhmc.edu.cn
}

\begin{abstract}
Cultural tourism is a comprehensive industry, which has become the most dynamic emerging industry, especially for the ethnic areas with rich cultural resources but relatively backward economy. The development of cultural tourism has an important economic, cultural, social and ecological significance. Taking the tourism as a carrier to capitalize the village culture, not only has a broad market prospect, but also can solve the basic livelihood of the villagers, and can promote the protection and inheritance of the ethnic culture. Dashanping village has made a breakthrough in the value transformation of Yi ethnic culture. It shows that cultural tourism in ethnic villages can help villagers get rid of poverty, promote regional economic development and benefit the protection of ethnic culture. Through the interaction of tourism for poverty alleviation and culture spatial production, ethnic villages can change the previous protection mode of cultural fragmentation, and finally realize the sustainable protection and development of villages. In the process of tourism for poverty alleviation, we should maintain respect for the culture of ethnic villages and focus on the original ecology of culture, and devote to the balance and harmony of cultural heritage protection and villagers' life, development and natural environment protection.
\end{abstract}

Keywords: Culture and tourism, spatial production, ethnic villages, poverty alleviation

\section{INTRODUCTION}

It has become one of the main ways for most ethnic villages to get rid of poverty and achieve economic growth through the development of tourism. According to the opinions on promoting the reform and development of tourism issued by the State Council, we need to vigorously develop rural tourism, and promote the poverty-stricken areas to get rid of poverty and become rich. Since 2016, Sichuan Tourism Development Committee has clearly proposed to fully implement the rural tourism to enrich the people, and develop a series of theme tourism products including residence inns in ethnic villages.

Ethnic villages are not only the rich treasure of ethnic culture and Chinese excellent traditional culture, but also an important position to promote the revitalization of rural culture at present in China. Ethnic villages are typical representatives of rural forms in ethnic areas, which determines that village culture becomes the core attraction in the tourism for poverty alleviation and the development of ethnic villages. Therefore, it is necessary to build and expand the culture and tourism space on the basis of protecting and inheriting the village culture, so as to effectively connect the rich cultural resources of ethnic villages with the tourism market.

\section{LITERATURE REVIEW}

The western research on culture and tourism space involves management, economics, sociology, psychology and other theories. Quantitative research and qualitative research are carried out simultaneously. The methods of data collection mainly adopt survey and interview, supplemented by secondary data survey. The research content can be divided into two categories from the scale of research objects. One is to study the social relations, landscape features, community development, and cultural activities of the landlords and tourists on a larger scale. Scholars have studied the relationship between the artistic conception space of tourist destination and the overall perception of tourists, and how various spatial elements interact and influence in a spatial environment [1-3]. The other is to study the composition and structural relationship of culture and tourism space elements in small-scale accommodation and rural inn [4-5].

At present, there are some researches on culture and tourism spatial production in domestic academic circles, which can be divided into two stages from the process. The first stage is before 2011, which mainly pays attention to the spatial pattern, landscape design and resource protection of tourism development from the aspects of architectural planning and cultural protection [6-9]. The second research stage is from 2012 to now. The themes are mainly concentrated in the two fields of ethnic culture [10] and architectural landscape planning [11-12]. 
To sum up, the current academic research on culture and tourism spatial production pays more attention to the macro development mode than the whole process. There are some achievements in the research on the function realization and approaches of culture and tourism space in urban and rural planning and landscape environment design, but the research on the mechanism of production mode is less, especially on the development of tourism industry in ethnic areas. There is a lack of research on the relationship between the tourism for poverty alleviation and the production of culture and tourism space in ethnic villages.

\section{THE PRICIPLE OF CULTURE AND TOURISM SPATIAL PRODUCTION IN ENTHIC VILLAGES}

The principle of authenticity should be followed in the process of culture and tourism spatial production in ethnic villages. In the process of tourism development, we must maintain respect for village culture and focus on the connotation and original ecology of village. The local culture and national culture of ethnic villages do not exist in isolation, on the contrary, they are always closely combined with specific inheriting subjects, activity process, time and space field, life situation, scene atmosphere, emotional experience, cultural interaction and many other factors. The culture of ethnic villages is integrated into the villagers' daily life process, which is related to the unique local atmosphere and environment. Only with the help of the actual cultural context and the process of life, that is to say, in the culture and tourism space of ethnic villages, can the culture of ethnic villages really survive and continue, and realize the generation and expression of its significance. Even if it is not the original protection and inheritance of ethnic culture, at least the cultural memory and some cultural elements are preserved. The construction of tourism projects will inevitably impact on the survival mode of the culture of ethnic villages. It is necessary to constantly reform and innovate the development means, and carry out tourism development to meet the needs of the times on the basis of maintaining authenticity.

\section{THE PRODUCTION OF CULTURE AND TOURISM SPACE IN ENTHNIC VILLAGES: A CASE STUDY OF DASHANPING VILLAGE IN LEIBO COUNTY}

\subsection{Basic Situation of Dashanping Village}

Dashanping village is located in Leibo County, eastern of Liangshan, is a pure $\mathrm{Yi}$ ethnic village for ecological migration in 2002. There are 5 villagers' groups, 193 families, with a population of 944. In 2016, there were 60 households and 319 poverty-stricken households with registered cards, with a poverty incidence rate of $33.8 \%$. It was one of 171 poverty-stricken villages in Leibo County. Dashanping village adheres to the concept of tourism for poverty alleviation, vigorously develops the green ecological economy, and promotes the sustainable, healthy and rapid development of rural tourism in the whole village. Dashanping village has been awarded the titles of "National Key Village for Poverty Alleviation through Rural Tourism".

\subsection{Tourism Infrastructure: Physical Space of Ethnic Village}

Before the relocation, the living conditions of Dashanping village were poor, the land was barren, the slope was steep and the road was dangerous. The basic necessities needed to be carried by horses, the draught was inconvenient, and there were many difficulties in education, medical treatment, etc. In 2002, the village moved to Leimaping farm, where the forest is dense. There are a lot of Cryptomeria, which takes several people to hold the thick trunk. Hence the name of Dashanping village. The village has strengthened tourism infrastructure construction, realized the full coverage of water, electricity and communication channels, and carried out landscape transformation of key areas and important nodes, such as field road, villagers' square and gate, highlighting the characteristics of Yi ethnic. There are more than 100 meters of cultural walls on the square, which are painted with totem worship patterns such as eagles and torches, as well as scenes such as farming, singing, dancing, etc., reflecting the strong folk customs.

\subsection{Tourism Project: Representation Space of Ethnic Village}

Dashanping village integrates the modern rural construction into the tourism projects, and improves the tourism supporting functions in accordance with the requirements of six elements of tourism. There were 43 poor farmers assisted in 2016, and each household invested about 20000 yuan to help improve the living environment. The traditional fire pool has been replaced by biogas and electromagnetic stove. The village committee adopts the traditional architectural style of Yi ethnic with yellow walls and blue tiles, which is the most striking sign of Dashanping. The village aims to build the most beautiful village in the east Liangshan, deeply tap the potential of rural tourism resources, and build tourism projects such as Yi paradises, sightseeing trails, and water shield vegetable bases. In addition, there are Yi cultural theme promenade, a lake viewing platform, circular sightseeing belts, a wetland park, cold water fish leisure gardens and other projects. In the Yi embroidery village of Mahu mansion founded by Jijue Lashi, the village's rich 
leader, the production of cultural handicrafts such as Yi embroidery, lacquerware and straw weaving not only enriches the cultural experience of tourists, but also helps more than 30 women in the village.

\subsection{Yi Ethnic Residence Inn: Living Inheritance Space of Intangible Cultural}

The Yi people in Liangshan call themselves Nuosu, which history can be traced back to ancient times. Characteristic residence is the living fossil of Yi ethnic. Dashanping village has invested 21.881 million yuan to encourage the villagers to build up the standard home-stay, and provide the tourists with the cultural experience of Yi customs with the residence inn as the carrier, such as eating Tuotuo meat, listening to the high tune of $\mathrm{Yi}$, and watching the back bride. The residence inn with the theme of Yi ethnic is popular with tourists. Jigen Buqie, who returned home a years ago and now plans to operate a residence inn. He said that Dashanping is a provincial demonstration village of tourism for poverty alleviation and a national key village for rural tourism for poverty alleviation. It has the opportunity to run a residence inn successfully. Guests can come to experience authentic Yi ethnic cuisine and learn Yi songs and dances.

\section{THE INTERACTION BETWEEN TOURISM FOR POVERTY ALLEVIATION AND CULTURE SPATIAL PRODUCTION IN ETHNIC VILLAGES}

\subsection{Integration of Tourism Resource Increases the Publicity of Space}

The public space in an ethnic village is not only a place for rural residents to enter and leave freely, and carry out various exchanges and recreation, but also an important place for ethnic cultural heritage. With the development of rural tourism and the external subjects have been involved in it, the publicity of villages' space has been enhanced, which makes the original relatively single space gradually transformed into the space including tourists, foreign investors, and other participants. Meanwhile, the function, landscape characteristics, utilization characteristics and other aspects of the original village public space have changed. In the tourism for poverty alleviation since 2016, Dashanping village pays great attention to the preservation of various forms of Yi cultural activity places including sacrifice, leisure, entertainment, etc. At the same time, the village has built a large amount of public space for tourists to sightseeing and experience, such as $\mathrm{Yi}$ traditional houses, ethnic customs exhibition halls, festivals squares, special restaurants and so on, thus the tourists are convenient to experience the Yi cultural of ethnic villages in a short distance. The Yi ethnic residence is a private space, but the residence inn for tourists is a public space. The private life of the operator is combined with the business activities of the inn, and the rich life atmosphere becomes the selling point to attract tourists.

\subsection{Tourism Expands Cultural Capital Space of Villages}

Ethnic villages are the carriers of cultural space, and tourism for poverty alleviation is the mode of economic development and transformation of cultural resources. They take the village cultural elements as the combination point, and they are interdependent and influence each other. Ethnic villages are rich in culture, such as ethnic architecture, festivals, crafts, cuisine, medicine, ethnic costumes, etc. While the tourism for poverty alleviation realizing the cultural capitalization of ethnic villages, it has the significance of expanding the capital space, and formulate and regulate the behavior of each participant, finally to obtain economic benefits. When tourism becomes a development path of social and economy, and ethnic culture becomes a resource, tourism can exist as a way of ethnic culture capitalization [13]. Dashanping village has made remarkable achievements in the value transformation of cultural resources, which shows that cultural tourism in ethnic villages can help villagers get rid of poverty, and promote the protection of ethnic culture. To expand the cultural capital space of villages through rural tourism not only has a broad market prospect, but also can promote the protection and inheritance of culture in ethnic villages.

\subsection{Optimize Space Production Mechanism with the Ethnic Residence Inn as a Carrier}

The characteristics of culture in ethnic villages determine the mode of rural tourism, and then determine the mode of cultural space production: ecological museum. This mode aims to pursue the balance and harmony between the protection of cultural heritage of ethnic villages and the protection of villagers' life, development and natural environment. There are some profit-making performance and experiential shopping, which leads to vulgarization and lack of unique cultural experience that ethnic villages should have. To get around the problem, the government has been actively promoting the construction of Yi ethnic residence inns in eastern Liangshan (table 1) since 2016. Leibo County, where Dashanping village is located, has the largest number of Yi ethnic residence inns. 
Table 1 Yi ethnic residence inns in eastern Liangshan

\begin{tabular}{|c|c|c|c|c|c|c|c|}
\hline County & Leibo & Jinyang & Meigu & Zhaojue & Butuo & Xide & Puge \\
\hline $\begin{array}{l}\text { The number of } \\
\text { Residence inns }\end{array}$ & 20 & 5 & 5 & 5 & 5 & 5 & 10 \\
\hline
\end{tabular}

The Yi ethnic residence inns in Dashanping village prove that the concept of ecological museum enters into the space production of culture and tourism of ethnic villages, can remember the culture of villages, realize the double benefits of cultural inheritance and development of tourism economy. It is a feasible way for ethnic villages to develop the rural tourism from the construction of residence inns, which not only meets to needs of current tourism consumption "from the purpose to the process", but also preserves the cultural essence in a living way.

\section{CONCLUSION}

With the development of tourism for poverty alleviation, some of the culture in ethnic villages has been separated from the life of villagers, even lost the original survival soil. It is the contradiction between the development of tourism and the cultural protection and inheritance of ethnic villages. Ethnic villages are not ordinary villages because the unique cultural resources will be damaged and difficult to repair. The tourism development of Dashanping village shows that the cultural tourism products of ethnic villages have a strong authenticity by restoring the local culture and ethnic culture to a specific cultural space. The culture and tourism space of ethnic villages is an organic whole. Therefore, it is necessary to understand the interaction between tourism for poverty alleviation and cultural spatial production in ethnic villages. We should make full use of the cultural endowment of ethnic villages, creatively transform the value of village culture, and make it continue to be the living part of the life of the villagers, so as to give full play to the tourism empowerment effect of national culture.

\section{ACKNOWLEDGMENT}

This work was financially supported by National Social Science Fund of China (No. 19BJY210), Sichuan Ethnic Mountain Economic Development Research Center (the Key Research Base of Humanities and Social Sciences of Sichuan Education Department, No. SDJJ1815), Research Center of Yi Culture (Sichuan Key Research Base of Philosophy and Social Sciences, No. YZWH1821).

\section{REFERENCES}

[1] Echtner M, Ritchie J. The meaning and measurement of destination image. The Journal of Tourism Studies. 2 (2) (1991) 2-12.

[2] Shibata T. Image formation process. Journal of Travel \& Tourism Marketing. 2(2-3) (1993) 191-216.

[3] Mazanec J A . Image measurement with selforganizing maps: A tentative application to Austrian tour operators. Tourism Review. 49(3) (1994) 9-18.

[4] Mansfeld Y. From motivation to actual travel. Annals of Tourism Research. 19(3) (1992) 399-419.

[5] Cederholm E A, Hultman J. The Value of intimacynegotiating commercial relationships in lifestyle entrepreneurship. Scandinavian Journal of Hospitality \& Tourism. 10(1) (2010) 16-32.

[6] Li Leilei. Semiotics and cultural studies of seashore tourism space. Journal of urban planning. (2) (2004) 58$6+96$.

[7] Li Cong. Production consumption model of tourism space from the perspective of political economy. Journal of Hubei University of Economics (Humanities and Social Sciences Edition). (1) (2009) 39-40.

[8] Wang Fenglong, Liu Yungang. Review and prospect of space production research. Human geography. (2) (2011) 13-19.

[9] Sun Likun, Zhang Zhenguo. Study on the spatial development mode of ethnic cultural tourism based on the point axis theory-Taking Tumen City of Yanbian as an example. Journal of Dalian University of nationalities. 13 (2) (2011) 141-143.

[10] Guirong, lv Wanqing. On the spatial production of ethnic cultural tourism. Human geography. (3) (2013) 154160.

[11] Hou Bing, Huang Zhenfang, Xu Haijun. Study on the spatial form of cultural tourism: a review and Enlightenment Based on cultural space. Journal of tourism. (03) (2011) 71-78.

[12] Jiang Kaiqiang. Research on methods of renewal and transformation of cultural tourism space-on cultural 
activation and tourism transformation. Sichuan Architecture. (4) (2016) 32-33.

[13] Pan Bao. Tourism as a way of national culture capitalization. Guangxi ethnic studies. (3) (2013) 183-189. 